\title{
Pragmatic study of a thromboprophylaxis algorithm in critically ill patients with SARS-COV-2 infection
}

\author{
Maurizio Fattorutto ${ }^{1}$ (D) Yves Bouckaert ${ }^{2} \cdot$ Jonathan $^{\text {Brauner }}{ }^{3} \cdot$ Stéphane Franck $^{2} \cdot$ Fabrice Bouton $^{2}$. \\ Danielle Heuse $^{2} \cdot$ Charlotte Bouckaert $^{4} \cdot$ Arnaud Bruyneel $^{2,5}$
}

Accepted: 16 June 2021 / Published online: 26 June 2021

(c) The Author(s), under exclusive licence to Springer Science+Business Media, LLC, part of Springer Nature 2021

\begin{abstract}
The optimal thromboprophylactic strategy for patients affected by Coronavirus disease 2019 (COVID-19) has been debated among experts. This study evaluated the safety and efficacy of a thromboprophylaxis algorithm. This was a retrospective, single-center study in critically ill patients admitted to the intensive care unit (University affiliated Hospital) for acute respiratory failure due to Severe Acute Respiratory Syndrome-Coronavirus 2 (SARS-CoV-2). From March 16 to April 9 , 2020, thromboprophylaxis was adjusted according to weight (control group, $\mathrm{n}=19$ ) and after this date, thromboprophylaxis depended on an algorithm based on thrombotic and hemorrhagic risk factors (protocol group, $\mathrm{n}=13$ ). With regard to safety (number of major bleeding events and blood transfusions), the groups were not significantly different. With regard to efficacy, the number of thrombotic events decreased from 37 to $0 \%, p=0.025$ after implementation of the algorithm. Also, peak fibrinogen dropped from 8.6 (7.2-9.3) to 6.5 (4.6-8.4) $\mathrm{g} / \mathrm{L}, p=0.041$ and D-dimers from 2194 (1464-3763) to 1486 $(900-2582) \mathrm{ng} / \mathrm{mL}, p=0.0001$. In addition, length of stay declined from 19 (10-31) to 5 (3-19) days, $p=0.009$. In conclusion, a tailored thromboprophylaxis algorithm (risk stratification based on clinical parameters and biological markers) reduce thrombotic phenomena in critically ill COVID-19 patients without increasing major bleeding.
\end{abstract}

Keywords COVID-19 $\cdot$ SARS-CoV-2 $\cdot$ Anticoagulation $\cdot$ Thrombosis $\cdot$ Hypercoagulability

\section{Highlights}

- "COVID-19-associated coagulopathy" (CAC) is characterized by the development of thrombotic events.

- The frequency of thrombotic events in patients with COVID-19 is high.

Maurizio Fattorutto

maurizio.fattorutto@chu-tivoli.be

1 Department of Anesthesiology, Centre Hospitalier Universitaire Tivoli, Avenue Max Buset 34, 7100 La Louvière, Belgium

2 Intensive Care Unit, Centre Hospitalier Universitaire Tivoli, La Louvière, Belgium

3 Department of Clinical Biology/Blood Bank, Centre Hospitalier Universitaire Tivoli, La Louvière, Belgium

4 Werfen N.V./S.A., Excelsiorlaan $48-50$ boite 8, Zaventem, Belgium

5 School of Public Health, Université Libre Bruxelles, Brussels, Belgium
- Major bleeding complications in patients infected with SARS-CoV-2 remain much less frequent.

- A tailored thromboprophylaxis algorithm (risk stratification based on clinical parameters and biological markers) reduced thrombotic complications of CAC without increasing major bleeding.

\section{Introduction}

In the practical advice for the prevention of thrombosis and the management of coagulation dysfunction associated with coronavirus disease 2019 (COVID-19), several experts used the terminology "COVID-19-associated coagulopathy" (CAC) [1, 2]. Clinically, CAC is distinguished by a hypercoagulable state leading to the development of thrombotic events (TE) [3-9]. One of the first provisional guidelines from medical societies and expert groups (posted online between March 25 and April 3, 2020) highlighted the importance of following standard hemostasis measurements. However, a year later, the evidence-based thromboprophylaxis 
approach for critically ill COVID-19 patients is still being developed [1,10-13] and current recommendations are based on expert opinions (https://www.covid19treatmen tguidelines.nih.gov/antithrombotic-therapy/).

In this setting, we have developed and implemented an algorithm that integrates biological and clinical factors with the aim of optimizing the anticoagulant management of patients severely affected by COVID-19 and admitted to the intensive care unit (ICU). The research statement was as follows: Is the use of an empiric thromboprophylaxis algorithm for critically ill COVID-19 patients effective on the basis of (a) clinically significant events (i.e., the number of TE documented based on radiological analysis and/or surgical exploration), (b) reduction in biological markers (i.e., the levels of D-dimers and fibrinogen in both groups), and (c) the number of adverse events, specifically major hemorrhagic events and blood transfusions?

\section{Materials and methods}

\section{Study design}

This was a retrospective study before/after implementation of a thromboprophylaxis protocol spread over a period of 3 months from March 16 to June 16, 2020, concerning 32 consecutive patients treated in the ICU at the Centre Hospitalier Universitaire Tivoli (CHU Tivoli), La Louvière, Hainaut, Belgium. This study was approved on July 29, 2020 by the ethics committee of the CHU Tivoli (number 1362). The creation of the thromboprophylaxis algorithm for patients with severe COVID-19 was based on available literature data with a cut-off date of April 05, 2020 [1, 3-6, 11-17]. Our algorithm was implemented on April 09, 2020 [1, 3-6, 11-25]. Thus, the control group (CG) included 19 patients and the protocol group (PG) comprised 13 patients. Patients who were treated before April 09, 2020 received standard or boosted prophylaxis with low molecular weight heparin (LMWH), this was the CG in our analysis. The standard prophylactic dose of LMWH corresponded to enoxaparin 4000 IU daily, subcutaneous (s.c.) if body weight (bw) was $<100 \mathrm{~kg}$ or $6000 \mathrm{IU}$ daily, s.c. if bw was $>100 \mathrm{~kg}$. If the patient was placed on invasive mechanical ventilation or high flow oxygen therapy, boosted prophylaxis was prescribed (according to bw) twice daily (b.i.d.). After April 09, 2020 all patients had targeted management of heparin therapy based on the algorithm. Patients treated exclusively according to our algorithm were the PG in our analysis (Fig. 1). For more detailed information about the practical use of the algorithm, refer to supplementary file "Online Resource 1".

\section{Study population}

Included patients were (a) adults (18 years and older), (b) admitted to the ICU, (c) with acute hypoxemic respiratory failure characterized by a $\mathrm{PaO}_{2} / \mathrm{FiO}_{2}$ ratio $\leq 150 \mathrm{~mm} \mathrm{Hg}$ [26], and (d) SARS-CoV-2 viral infection confirmed by molecular reverse-transcription polymerase chain reaction (RT-PCR) using a swab sample from the respiratory tract [27]. For more detailed information about the standard treatment administered to the two groups and exclusion criteria, refer to supplementary files "Online Resources 2, 3".

\section{Laboratory tests}

All tests were performed in the hospital laboratory. The viscoelastic tests were performed on a ROTEM delta ${ }^{\mathrm{TM}}$ (Werfen, Instrumentation Laboratory, Bedford, MA, USA) according to the manufacturer's recommendations [28]. The ROTEM $^{\mathrm{TM}}$ assays have been presented in detail elsewhere [19, 20, 29]. Biomarkers of disease progression included C-reactive protein, white blood cell (WBC) count, neutrophil count, lymphocyte count, and neutrophil-to-lymphocyte ratio (NLR) [30]. For more detailed information about other laboratory tests, the normal limits, and analysis thresholds, refer to supplementary file "Online Resource 4".

\section{Baseline clinical characteristics}

We collected basic demographic data and medically-confirmed co-morbidities from the computerized patient record. Multi-morbidity referred to the presence of $\geq 3$ severe comorbidities identified before admission to the ICU: arterial hypertension, cerebrovascular disease (stroke/transient ischemic attack), diabetes mellitus, chronic kidney disease $>$ stage 3B [31], congestive heart failure, coronary disease (coronary artery bypass grafting and/or history of acute myocardial infarction), chronic obstructive pulmonary disease GOLD $\geq 2$ [32], metastatic carcinoma, obesity (body mass index $\geq 35$ ) [33]. We calculated $\mathrm{PaO}_{2} / \mathrm{FiO}_{2}$ ratio (first arterial blood gas analysis recorded during ICU admission) [26]. Finally, we calculated various scores, including the APACHE II score, the Sequential Organ Failure Assessment (SOFA) score [34], the disseminated intravascular coagulation score (DIC) [35, 36], and the IMPROVE bleeding risk score [22, 23]. The diagnosis of Acute Respiratory Distress Syndrome (ARDS) was made according to the Berlin 
Fig. 1 Tailored thromboprophylaxis algorithm for the prevention of thrombotic events in critically ill COVID-19 patients. Anti-FXa anti-factor $\mathrm{X}$ activated, $A P T T$ activated partial thromboplastin time, ATIII antithrombin III, GFR glomerular filtration rate, $H F O T$ high flow oxygen therapy, ICU intensive care unit, INR International Normalized Ratio, i.v. intravenous, $M C F-E X T E M^{\mathrm{TM}}$ maximum clot firmness, $E X E M^{\mathrm{TM}}$ assay measured on rotational thromboelastometry, s.c. subcutaneous, $U F H$ unfractionated heparin

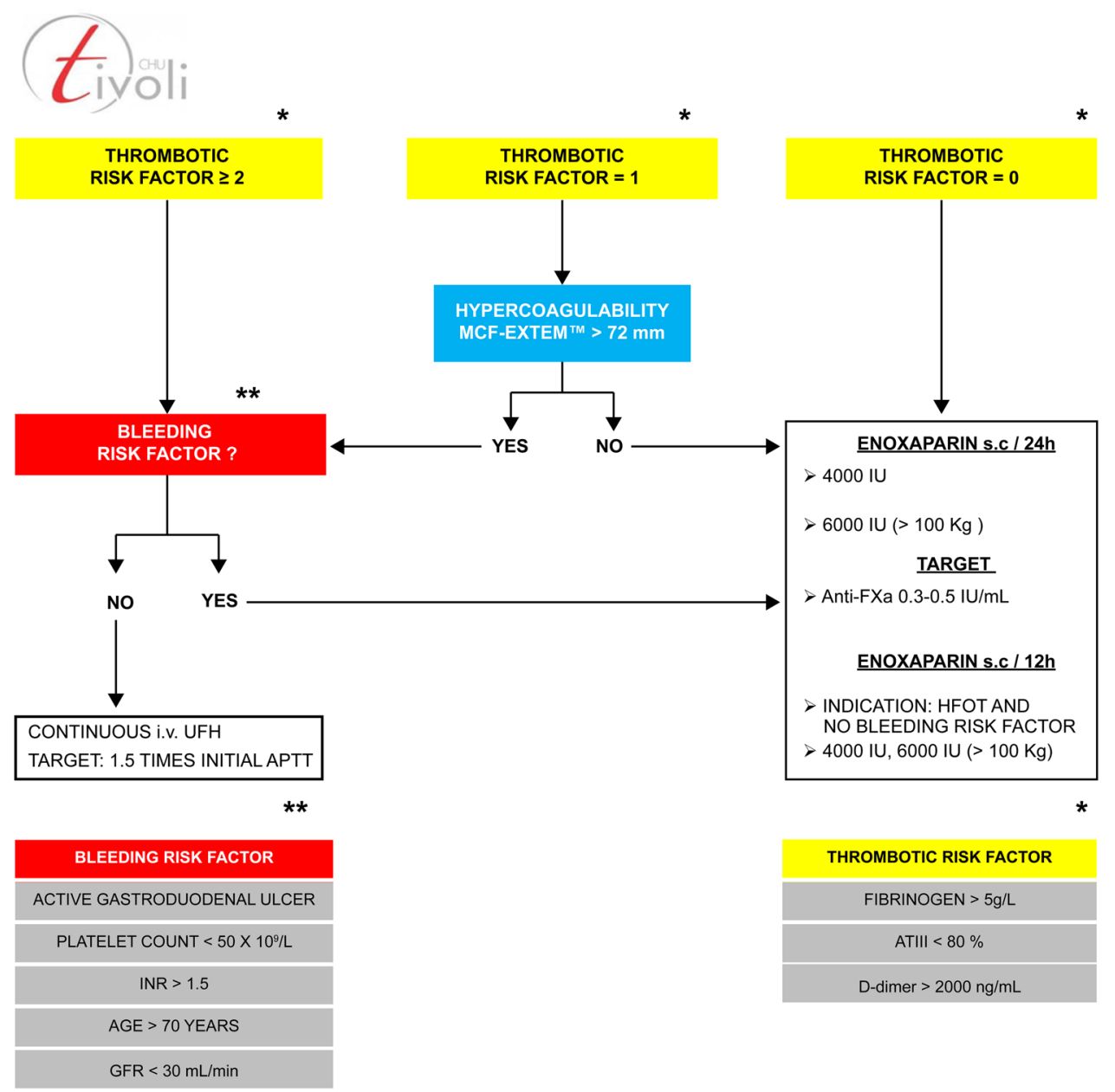

definition [37]. Septic shock had been set according to the international definition for sepsis and septic shock (third consensus) [38]. Major bleeding was defined according to the Subcommittee on Control of Anticoagulation of the Scientific and Standardization Committee of the International Society of Thrombosis and Hemostasis (ISTH) [39].

\section{Outcomes and clinical characteristics}

We documented clinical characteristics and outcomes as follows: (a) invasive mechanical ventilation and acute renal replacement therapy via a continuous veno-venous hemofiltration program PRISMAFLEX TM (Baxter, Brainel'Alleud, Belgium), (b) blood transfusions, (c) anti-coagulation regimens, (d) severe ARDS and septic shock and (e) TE (i.e., venous thromboembolism or arterial thrombosis), major bleeding and ICU mortality.

\section{Statistical analyses}

For comparisons of asymmetric variables, the Mann-Whitney $(\mathrm{U})$ and Kruskal-Wallis $(\mathrm{H})$ tests were used. For symmetric variables, Student's T ( $t)$ test and the Chi-square test $\left(\chi^{2}\right)$ were used for proportion comparisons. Statistical analyses were performed with Software for Statistics and Data Science (14.0, Texas, USA). Means and standard deviations ( \pm ) were used to describe symmetric variables. Median variables and Inter Quartile Range (IQR) were used to describe the asymmetric variables. Fisher's exact test was used when the frequencies were $\leq 5$. A $p$ value $<0.05$ was considered statistically significant. 


\section{Results}

\section{Baseline characteristics at admission (Table 1)}

There were no statistical differences between the groups in terms of demographic, clinical, and biological characteristics at baseline (Table 1). Fore more detailed information about characteristics, at baseline, in each group, refer to supplementary files "Online Resources $5-7 "$.

\section{Characteristics of the administered therapies (Table 2)}

The CG and the PG were not significantly different with regard to the use of the UFH "moderate regimen", 37\% vs $30 \%(p=1)$. No patients were ineligible to receive continuous i.v. UFH due to a risk of bleeding to begin with, according to the bleeding risk factors described in the algorithm (Fig. 1). Overall, the CG and the PG were not significantly different with regard to blood transfusions.
Table 2 Characteristics of administered therapies

\begin{tabular}{lcll}
\hline Characteristics & CG $(\mathrm{n}=19)$ & PG $(\mathrm{n}=13)$ & $p$ value \\
\hline UFH “moderate regimen" & $7(37 \%)$ & $4(30 \%)$ & 1 \\
Combination $\geq 2$ organ supports $^{\mathrm{b}}$ & $3(16 \%)$ & $3(23 \%)$ & 0.666 \\
RBC transfusion, units & $1(0-1)$ & $0(0-1)$ & 0.347 \\
Platelet transfusion, units & $0(0-0)$ & $0(0-0)$ & N/A \\
FFP transfusion, units & $0(0-0)$ & $0(0-0)$ & N/A \\
RBC and PC and FFP transfu- & $1(0-1)$ & $0(0-1)$ & 0.547 \\
$\quad$ sion, units & $10(53 \%)$ & $5(38 \%)$ & 0.490 \\
Patients transfused &
\end{tabular}

Values are expressed as a number (\%) or median (interquartile range) $C G$ control group, N/A not available, $P G$ protocol group, $U F H$ unfractionated heparin, $U F H$ "moderate regimen" means a target 1.5 times the initial APTT

${ }^{\text {a }}$ Doses of UFH did not exceed $400 \mathrm{IU} / \mathrm{Kg}$ daily

${ }^{\mathrm{b}}$ The combination of organ supports means the simultaneous presence of (i) invasive ventilation via trans-laryngeal intubation or tracheostomy or extracorporeal respiratory support, and (ii) acute renal replacement therapy via a continuous veno-venous hemofiltration program
Table 1 Demographic, clinical, and biological characteristics at baseline

\begin{tabular}{llll}
\hline Characteristics & $\mathrm{CG}(\mathrm{n}=19)$ & PG $(\mathrm{n}=13)$ & $p$ value \\
\hline Age, years & $61.8 \pm 12.5$ & $64.1 \pm 14.8$ & 0.629 \\
Male sex & $11(58 \%)$ & $11(85 \%)$ & 0.141 \\
$\mathrm{Co}_{-}$morbidity $\geq 3^{\mathrm{a}}$ & $5(26 \%)$ & $4(31 \%)$ & 1 \\
$\mathrm{PaO}_{2} / \mathrm{FiO}_{2}$ ratio D+1, mmHg & $92(65-100)$ & $69(55-81)$ & 0.161 \\
$\mathrm{APACHE} \mathrm{II} \mathrm{score}_{\text {SOFA score }}$ & $17(10-46)$ & $17(8-29)$ & 0.331 \\
IMPROVE bleeding risk score & $4(2-7)$ & $4(2-8)$ & 0.218 \\
Fibrinogen D+1, g/L & $7(4-12)$ & $7.5(2.5-4)$ & 0.480 \\
ATIII activity D+1, \% & $4.9(4.7-7.5)$ & $4.5(4.6-7.9)$ & 0.208 \\
D-dimers D+1, ng/mL FEU & $66(56-87)$ & $94(78-106)$ & 0.090 \\
C-reactive protein D+1, mg/L & $1847(1443-4841)$ & $1146(88-2492)$ & 0.265 \\
LOS (before ICU admission), days & $159(97-269)$ & $122(57-197)$ & 0.185 \\
\hline
\end{tabular}

Values are expressed as mean \pm standard deviation, number (\%), or median (interquartile range)

APACHE II acute physiology and chronic health evaluation II, ATIII antithrombin III, CG control group, $D+1$ day one after admission to intensive care unit, FEU fibrinogen equivalent units, IMPROVE international medical prevention registry on venous thromboembolism, $L O S$ length of stay in a non-critical COVID-19 unit, $\mathrm{PaO}_{2} / \mathrm{FiO}_{2}$ the ratio of arterial oxygen partial pressure $\left(\mathrm{PaO}_{2}\right.$ expressed in $\left.\mathrm{mmHg}\right)$ to fractional inspired oxygen $\left(\mathrm{FiO}_{2}\right.$ expressed as a fraction), $P G$ protocol group $S O F A$ score sequential organ failure assessment score

${ }^{a}$ Multi-morbidity refers to the presence of $\geq 3$ severe co-morbidities: arterial hypertension, cerebrovascular disease (stroke/transient ischemic attack), diabetes mellitus, chronic kidney disease $>$ stage 3B, congestive heart failure, coronary artery disease (coronary artery bypass grafting and/or history of acute myocardial infarction), chronic obstructive pulmonary disease GOLD $\geq$ II, metastatic carcinoma, obesity (body mass index $\geq 35$ )

${ }^{\mathrm{b}}$ ATIII activity was not measured in 4/19 CG and 8/13 PG patients (non-performance of measurements in $21 \%$ and $38 \%$ of CG and PG, respectively, was due to study protocol according to the algorithm) 
Table 3 Clinical and biological measurements

\begin{tabular}{llll}
\hline Characteristics & CG $(\mathrm{n}=19)$ & PG $(\mathrm{n}=13)$ & $p$ value \\
\hline IMV, days & $19(7-42)$ & $13(1-19)$ & 0.199 \\
IMV & $13(68 \%)$ & $6(46 \%)$ & 0.055 \\
ICU LOS, days & $19(10-31)$ & $5(3-19)$ & 0.009 \\
ISTH-DIC score $\geq 5$ & $0(0 \%)$ & $0(0 \%)$ & N/A \\
Fibrinogen peak, g/L & $8.6(7.2-9.3)$ & $6.5(4.6-8.4)$ & 0.041 \\
ATIII activity, \% & $60.5(41-125)$ & $67(18-98)$ & 0.516 \\
Anti-FXa activity, IU/mL & $0.66(0.39-0.73)$ & $0.44(0.30-0.65)$ & 0.001 \\
D-dimers, ng/mL FEU & $2194(1464-3763)$ & $1486(900-2582)$ & 0.0001 \\
ROTEM MCF-EXTEM ${ }^{\mathrm{T} M}, \mathrm{~mm}$ & $\mathrm{~N} / \mathrm{A}$ & $77(69-82)$ & $\mathrm{N} / \mathrm{A}$ \\
TE & $7(37 \%)$ & $0(0 \%)$ & 0.025 \\
Severe ARDS & $9(47 \%)$ & $4(31 \%)$ & 1 \\
Septic shock & $3(16 \%)$ & $2(15 \%)$ & 1 \\
Major bleeding & $1(5 \%)$ & $2(15 \%)$ & 1 \\
Mortality & $4(21 \%)$ & $4(31 \%)$ & 0.683 \\
\hline
\end{tabular}

Values are expressed as median (interquartile range) or number (\%)

$A R D S$ acute respiratory distress syndrome, ATIII antithrombin III, Anti-FXa anti-factor Xa, CG control group, FEU fibrinogen equivalent units, $I C U$ intensive care unit, $I M V$ invasive mechanical ventilation, ISTH-DIC score International Society for Thrombosis and Hemostasis-Disseminated Intravascular Coagulation score, $L O S$ length of stay, $M C F$ maximum clot firmness, $N / A$ not available, $P G$ protocol group, $T E$ thrombotic events (TE corresponded to 1 pulmonary embolism, 2 splanchnic ischemias, 2 strokes, 1 renal infarction, and 1 splenic infarction)

${ }^{a}$ Fibrinogen peak corresponds to the highest value during the stay measured at least twice over a $24-\mathrm{h}$ interval

\section{Outcomes, clinical and biological characteristics (Table 3)}

While there was a non-significant trend in shorter duration of invasive mechanical ventilation of 13 (1-19) vs 19 (7-42) days $(p=0.199)$, between the PG compared to $\mathrm{CG}$, there were fewer patients on invasive mechanical ventilation $46 \%$ vs $68 \%$ ( $p=0.055)$, respectively, while the ICU length of stay was statistically and remarkably shorter 5 (3-19) vs $19(10-31)$ days $(p=0.009)$, respectively.

Regarding biological profiles, the fibrinogen peak, measured during the ICU stay, was associated with a significant difference between the CG and the PG, with 8.6 (7.2-9.3) vs $6.5(4.6-8.4) \mathrm{g} / \mathrm{L}(p=0.041)$, respectively. For more detailed information about the fibrinogen peaks in each group, refer to supplementary files "Online Resource 8, 9". The ATIII activities were not significantly different between the CG and the PG but below the lower limit of normality. However, D-dimers were statistically and remarkably lower, 1486 (900-2582) vs 2194 (1464-3763) ng/mL, between the PG and the CG $(p=0.0001)$, respectively. Similarly, measurements of anti-FXa activity (measured at peak, $4 \mathrm{~h}$ after administration) were significantly lower in the PG compared to the CG, $0.44(0.30-0.65)$ vs $0.66(0.39-0.73)$ $\mathrm{IU} / \mathrm{mL}(p=0.001)$, respectively. Nine patients in the PG underwent viscoelastic analyses according to the algorithm (Fig. 1). The MCF-EXTEM ${ }^{\mathrm{TM}}$ was measured at 77 (69-82) $\mathrm{mm}$, outside the upper limit of normality. For more detailed information about the MCF-EXTEM ${ }^{\mathrm{TM}}$ measurements, refer to supplementary file "Online Resource 10".

Concerning outcomes, the number of TE was statistically different $37 \%$ vs $0 \%$, between the CG and the PG $(p=0.025)$, respectively. Overall, the CG and the PG were not significantly different for the number of patients affected by major bleeding $5 \%$ vs $15 \%(p=1)$, respectively. At the level of mortality, no statistical distinction could be identified between the CG and the PG, $21 \%$ vs $31 \%(p=0.683)$, respectively.

\section{Discussion}

With regard to safety, the implementation of our algorithm did not increase major bleeding rate and our results were in line with previous observations [40, 41]. For example, in a retrospective study $(\mathrm{n}=42$ patients) from Pavoni et al. notwithstanding the use of the administered anticoagulation regimen (intermediate dose enoxaparin $4000 \mathrm{IU}$ or $6000 \mathrm{IU}$ if body mass index $>35$, s.c., b.i.d., or therapeutic dose enoxaparin $100 \mathrm{IU} / \mathrm{Kg}$ s.c., b.i.d.), no major hemorrhagic event was observed [40]. The controlled study, before/after implementation of a "more aggressive" thromboprophylaxis 
protocol, from Stessel et al. involved 72 patients treated preventively with LMWH: a group of 46 patients treated with a low-dose thromboprophylaxis regimen (control group, nadroparin $2850 \mathrm{IU} /$ daily, s.c.) and a group of 26 patients treated with an intensified thromboprophylaxis protocol (intervention group, nadroparin 3800 IU b.i.d., s.c.). The authors reported only one episode of bleeding [41].

With regard to efficacy, our results were in line with observations from various studies focused on TE and higher intensity thromboprophylaxis in COVID-19 ICU patients [42-44]. Several multicenter studies have demonstrated the ineffectiveness of prescribed-dose-prophylactic LMWH in COVID-19 patients [42, 43]. In a retrospective singlecenter study ( $\mathrm{n}=188$ patients), an escalated-dose thromboprophylaxis strategy was implemented according to D-dimer levels and clinical and biological parameters [44]. The use of high-intensity prophylaxis treatment (enoxaparin $40 \mathrm{mg}$ b.i.d. in 75 patients) was associated with a lower incidence of TE (12.2\%), without increasing major bleeding. According to Atallah et al. the lower rate of TE may be related to the implementation of their tailored thromboprophylaxis approach [44].

With regard to the results of biological measurements, we were also in accordance with numerous reports. First, ATIII activity was decreased well below the lower limit of normality which was close to the findings from various studies $[3,5$, $6,42,45]$. Second, the MCF- EXTEM ${ }^{\mathrm{TM}}$ assays were outside the upper limit of normality which corroborated the work of other investigators [46-56]. These observations remain to be confirmed and, the international multicenter observational ROHOCO study (ROtem analysis and standard coagulation tests in HOspitalized patients with COvid-19) has completed its patient recruitment phase and the trial results are pending (https://www.drks.de/drks_web/). Third, the results of this study are in line with current observations regarding the amplification of fibrinogen and D-dimer levels well beyond the limits of normality [3-6, 8, 42, 45, 57]. It appears that an increase in D-dimers and fibrinogen levels produces hypercoagulability leading to pulmonary micro-thrombi and poor clinical outcomes in COVID-19 patients $[4,5,58$, 59]. After implementation of the algorithm, the decreases in D-dimer levels and fibrinogen peaks as well as the trend toward shorter invasive mechanical ventilation duration and a statistically significantly shorter ICU length of stay, reinforced our conviction that a tailored anticoagulant algorithm (risk stratification based on clinical parameters and biological markers) could reduce thrombotic phenomena. This theory may correspond to a previously published report in critically ill COVID-19 patients [60]. In the first randomized controlled trial of anticoagulant therapy in patients with COVID-19 ( $n=20$ patients), Lemos et al. compared preventive or therapeutic anticoagulation in patients requiring invasive mechanical ventilation [58]. Administration of therapeutic-dose showed improvement in $\mathrm{PaO}_{2} / \mathrm{FiO}_{2}$ ratios after 7 and 14 days, decreased D-dimer levels, and, particularly, the number of ventilator-free days compared with prophylactic dose anticoagulation (15 [IQR 6-16] vs 0 [IQR $0-11]$ days, $p=0.028$ ) $[60,61]$.

With regard to baseline thrombotic risk, it was also important to analyze the similarities between the compared groups, refer to supplementary files "Online Resources 5-7, $11 "$.

With regard to undeniable limitations, this study was limited in its mono-centric design, small sample size, retrospective nature, and the possible interference of confounding variables. Other factors contributing to an underestimation or overestimation of an outcome could bias our assessment. For example, none of the TE had been diagnosed by computed tomography angiography, so events reports were potentially subject to reporting bias. Lastly, our algorithm was set up on April 09, 2020 systematically in all patients affected by COVID-19 admitted to the ICU. Therefore, patients included in the CG who were still being treated in the ICU also benefited from this algorithm from the above-mentioned date. This treatment bias (overlapping therapies) could have altered the results as reported by Stessel et al. [41].

\section{Conclusions}

Our observations show that implementation of a pragmatic and easy-to-use, tailored anticoagulant algorithm (risk stratification based on clinical parameters and biological markers) can reduce thrombotic phenomena. In terms of safety of care, the use of a supra-preventive heparin therapy strategy did not appear to be associated with higher rates of major bleeding or blood transfusions. Although it appears that supra-preventive heparin administration reduced thrombotic phenomena, it did not change mortality. It is clear that the true magnitude of this study must be considered in light of the undeniable limitations of its observations. The external validation of these results into current practice assumes large sample size, randomized studies with control groups and, at the time of the writing this manuscript, several randomized studies to assess the efficacy/safety of anticoagulant prophylaxis strategies in critically ill COVID-19 patients are currently recruiting participants [62].

Supplementary Information The online version of this article (https:// doi.org/10.1007/s11239-021-02514-3) contains supplementary material, which is available to authorized users.

Acknowledgements The patient care presented in detail in this paper will remain one of our most memorable professional experiences. We would like to thank all the members of the intensive care team with a specific mention of the doctors who actively contributed to the implementation of the pragmatic algorithm, in alphabetical order: Abbatoy 
I, Audiat C, Carpentier D, Ceruti H, De Becker B, De Leener F, Fasseaux A, Jeandriens A, Leclercq M, Molls G, Pingitore J, Riga JP, and Sadis C. The authors would like to acknowledge the contribution of a medical writer, Sandy Field, PhD, for English language editing of this manuscript.

Author contributions Study conception and design were performed by MF. Material preparation, data collection and analysis were performed by MF, JB, YB, SF, FB, DH, CB and AB. The first draft of the manuscript was written by MF and all authors commented on previous versions of the manuscript. Formal analysis was carried out by AB. All authors read and approved the final manuscript.

Funding This research did not receive any specific grant from funding agencies in the public, commercial, or not-for-profit sectors.

Data availability On request, the authors have made these data available to the editors during the peer-review process.

\section{Declarations}

Conflict of interest The authors declare no conflicts of interest/competing interests. Authors declare to adhere to the minimum reporting guidelines hosted by the EQUATOR Network when preparing their observational study (STROBE statement).

Ethical approval This retrospective study, involving human participants, was in accordance with the ethical standards of the institutional and/or national research committee and with the 1964 Helsinki Declaration and its later amendments or comparable ethical standards. The ethics committee of the Centre Hospitalier Universitaire Tivoli, La Louvière, Hainaut, Belgium (Université Libre Bruxelles, Bruxelles, Belgium) approved this study on July 29, 2020 (Number 1362).

Informed consent Formal informed consent was exempted by the ethics committee of our hospital due to the retrospective nature of the study and given the risks of awakening a painful past or of calling on a family to process data from a deceased person. No patient expressed opposition to the use of their medical records for research and/or publication purposes. This wish was respected by checking in each computerized medical file whether an objection form was archived in the "clinical research" section.

\section{References}

1. Hunt B, Retter A, McClintock C (2020) Practical guidance for the prevention of thrombosis and management of coagulopathy and disseminated intravascular coagulation of patients infected with COVID-19. https://b-s-h.org.uk/media/18171/th-and-covid-25march-2020-final.pdf. Accessed 30 Mar 2020

2. Connors JM, Levy JH (2020) COVID-19 and its implications for thrombosis and anticoagulation. Blood 135(23):2033-2040. https://doi.org/10.1182/blood.2020006000

3. Tang N, Li D, Wang X et al (2020) Abnormal coagulation parameters are associated with poor prognosis in patients with novel coronavirus pneumonia. J Thromb Haemost 18(4):844-847. https://doi.org/10.1111/jth.14768

4. Wang D, Hu B, Hu C et al (2020) Clinical characteristics of 138 hospitalized patients with 2019 novel coronavirus-infected pneumonia in wuhan, China. JAMA 323(11):1061-1069. https://doi. org/10.1001/jama.2020.1585
5. Zhou F, Yu T, Du R et al (2020) Clinical course and risk factors for mortality of adult inpatients with COVID-19 in Wuhan, China: a retrospective cohort study. Lancet 395(10229):1054-1062. https://doi.org/10.1016/S0140-6736(20)30566-3

6. Han H, Yang L, Liu R et al (2020) Prominent changes in blood coagulation of patients with SARS-CoV-2 infection. Clin Chem Lab Med 58(7):1116-1120. https://doi.org/10.1515/ cclm-2020-0188

7. Wright FL, Vogler TO, Moore EE et al (2020) Fibrinolysis shutdown correlates to thromboembolic events in severe COVID-19 infection. J Am Coll Surg 231(2):193-203.e1. https://doi.org/10. 1016/j.jamcollsurg.2020.05.007

8. Guan W-j, Ni Z-y, Hu Y et al (2020) Clinical characteristics of coronavirus disease 2019 in China. N Engl J Med 382:1708-1720. https://doi.org/10.1056/NEJMoa2002032

9. Levi M, Iba T (2021) COVID-19 coagulopathy: is it disseminated intravascular coagulation? Intern Emerg Med 16(2):309-312. https://doi.org/10.1007/s11739-020-02601-y

10. Salabei JK, Fishman TJ, Asnake ZT et al (2021) COVID-19 Coagulopathy: current knowledge and guidelines on anticoagulation. Heart Lung 50(2):357-360. https://doi.org/10.1016/j.hrtlng.2021. 01.011

11. Thachil J, Tang N, Gando S et al (2020) ISTH interim guidance on recognition and management of coagulopathy in COVID-19. J Thromb Haemost 18(5):1023-1026. https://doi.org/10.1111/jth. 14810

12. Susen S, Tacquard CA, Godon A et al. (2020) Traitement anticoagulant pour la prevention du risque thrombotique chez un patient hospitalise avec covid-19 et surveillance de l'hemostase propositions du GIHP et du GFHT. https://sfar.org/traitement-anticoagul ant-pour-la-prevention-du-risque-thrombotique-chez-un-patie nt-hospitalise-avec-covid-19-et-surveillance-de-lhemostase/. Accessed 3 Apr 2020

13. COVIDprotocols v2.0. Brigham and Women's Hospital/Partners in Health/UCSF Institute for Global Health Sciences (2021). https://www.covidprotocols.org. Accessed 30 Mar 2020

14. Tang N, Bai H, Chen X et al (2020) Anticoagulant treatment is associated with decreased mortality in severe coronavirus disease 2019 patients with coagulopathy. J Thromb Haemost 18(5):1094 1099. https://doi.org/10.1111/jth.14817

15. Wu C, Chen X, Cai Y et al (2020) Risk factors associated with acute respiratory distress syndrome and death in patients with coronavirus disease 2019 pneumonia in Wuhan, China. JAMA Intern Med 180(7):934-943. https://doi.org/10.1001/jamaintern med.2020.0994

16. Lin L, Lu L, Cao W et al (2020) Hypothesis for potential pathogenesis of SARS-CoV-2 infection-a review of immune changes in patients with viral pneumonia. Emerg Microbes Infect 9(1):727732. https://doi.org/10.1080/22221751.2020.1746199

17. Jin YH, Cai L, Cheng ZS et al (2020) A rapid advice guideline for the diagnosis and treatment of 2019 novel coronavirus (2019$\mathrm{nCoV}$ ) infected pneumonia (standard version). Mil Med Res 7(1):4. https://doi.org/10.1186/s40779-020-0233-6

18. Harahsheh Y, Ho KM (2018) Use of viscoelastic tests to predict clinical thromboembolic events: a systematic review and metaanalysis. Eur J Haematol 100(2):113-123. https://doi.org/10.1111/ ejh.12992

19. Görlinger K, Pérez-Ferrer A, Dirkmann D et al (2019) The role of evidence-based algorithms for rotational thromboelastometryguided bleeding management. Korean J Anesthesiol 72(4):297322. https://doi.org/10.4097/kja.19169

20. Williams B, McNeil J, Crabbe A et al (2017) Practical use of thromboelastometry in the management of perioperative coagulopathy and bleeding. Transfus Med Rev 31(1):11-25. https://doi. org/10.1016/j.tmrv.2016.08.005 
21. Akay OM (2018) The double hazard of bleeding and thrombosis in hemostasis from a clinical point of view: a global assessment by rotational thromboelastometry (ROTEM). Clin Appl Thromb Hemost 24(6):850-858. https://doi.org/10.1177/1076029618 772336

22. Decousus H, Tapson VF, Bergmann JF et al (2011) Factors at admission associated with bleeding risk in medical patients: findings from the IMPROVE investigators. Chest 139(1):69-79. https://doi.org/10.1378/chest.09-3081

23. Rosenberg DJ, Press A, Fishbein J et al (2016) External validation of the IMPROVE bleeding risk assessment model in medical patients. Thromb Haemost 116(3):530-536. https://doi.org/10. 1160/TH16-01-0003.Accessed30March2020

24. Massachusetts General Hospital COVID-19 treatment guidance. https://www.massgeneral.org/assets/MGH/pdf/news/coronavirus/ mass-general-COVID-19-treatment-guidance.pdf. Accessed 30 Mar 2020

25. World Health Organization (2020) Clinical management of severe acute respiratory infection (SARI) when COVID-19 disease is suspected: interim guidance. World Health Organization. https:// apps.who.int/iris/handle/10665/331446. Accessed 30 Mar 2020

26. Bourenne J, Carvelli J, Papazian L (2019) Evolving definition of acute respiratory distress syndrome. J Thorac Dis 11(Suppl 3):S390-S393. https://doi.org/10.21037/jtd.2018.12.24

27. CDC 2019-Novel Coronavirus (2019-nCoV) real-time RT-PCR diagnostic panel. https://www.fda.gov/media/134922/download. Accessed 30 Mar 2020

28. Roghani K, Holtby RJ, Jahr JS (2014) Effects of hemoglobinbased oxygen carriers on blood coagulation. J Funct Biomater 5(4):288-295. https://doi.org/10.3390/jfb5040288

29. Crochemore T, Piza FMT, Rodrigues RDR et al (2017) A new era of thromboelastometry. Einstein (Sao Paulo) 15(3):380-385. https://doi.org/10.1590/S1679-45082017MD3130

30. Ponti G, Maccaferri M, Ruini C et al (2020) Biomarkers associated with COVID-19 disease progression. Crit Rev Clin Lab Sci 57(6):389-399. https://doi.org/10.1080/10408363.2020.1770685

31. Levin A, Stevens PE (2014) Summary of KDIGO 2012 CKD guideline: behind the scenes, need for guidance, and a framework for moving forward. Kidney Int 85(1):49-61. https://doi.org/10. 1038/ki.2013.444

32. Pauwels RA, Buist AS, Calverley PM, GOLD Scientific Committee et al (2001) Global strategy for the diagnosis, management, and prevention of chronic obstructive pulmonary disease. NHLBI/WHO Global Initiative for Chronic Obstructive Lung Disease (GOLD) Workshop summary. Am J Respir Crit Care Med 163(5):1256-1276. https://doi.org/10.1164/ajrccm.163.5.2101039

33. Nuttall FQ (2015) Body mass index: obesity, BMI, and health: a critical review. Nutr Today 50(3):117-128. https://doi.org/10. 1097/NT.0000000000000092.Accessed20May2021

34. Rapsang AG, Shyam DC (2014) Scoring systems in the intensive care unit: a compendium. Indian J Crit Care Med 18(4):220-228. https://doi.org/10.4103/0972-5229.130573.Accessed20May2021

35. Drouet L (2010) CIVD: quoi de neuf au congrès de l'ISTH? (Boston, 2009). Sang Thromb Vaiss 22(3):42-46. https://doi.org/10. 1684/stv.2009.0442

36. Iba T, Levy JH, Warkentin TE et al (2019) Scientific and Standardization Committee on DIC, and the Scientific and Standardization Committee on perioperative and critical care of the international society on thrombosis and haemostasis. Diagnosis and management of sepsis-induced coagulopathy and disseminated intravascular coagulation. J Thromb Haemost 17(11):1989-1994. https:// doi.org/10.1111/jth. 14578

37. Fanelli V, Vlachou A, Ghannadian S et al (2013) Acute respiratory distress syndrome: new definition, current and future therapeutic options. J Thorac Dis 5(3):326-334. https://doi.org/10.3978/j.issn. 2072-1439.2013.04.05
38. Singer M, Deutschman CS, Seymour CW et al (2016) The third international consensus definitions for sepsis and septic shock (sepsis-3). JAMA 315(8):801-810. https://doi.org/10.1001/jama. 2016.0287

39. Schulman S, Kearon C (2005) Subcommittee on Control of Anticoagulation of the Scientific and Standardization Committee of the International Society on Thrombosis and Haemostasis. Definition of major bleeding in clinical investigations of antihemostatic medicinal products in non-surgical patients. J Thromb Haemost 3(4):692-694. https://doi.org/10.1111/j.1538-7836.2005.01204.x

40. Pavoni V, Gianesello L, Pazzi M et al (2020) Venous thromboembolism and bleeding in critically ill COVID-19 patients treated with higher than standard low molecular weight heparin doses and aspirin: a call to action. Thromb Res 196:313-317. https://doi.org/ 10.1016/j.thromres.2020.09.013

41. Stessel B, Vanvuchelen C, Bruckers L et al (2020) Impact of implementation of an individualised thromboprophylaxis protocol in critically ill ICU patients with COVID-19: a longitudinal controlled before-after study. Thromb Res 194:209-215. https:// doi.org/10.1016/j.thromres.2020.07.038

42. Helms J, Tacquard C, Severac F et al (2020) High risk of thrombosis in patients with severe SARS-CoV-2 infection: a multicenter prospective cohort study. Intensive Care Med 46(6):1089-1098. https://doi.org/10.1007/s00134-020-06062-x

43. Maatman TK, Jalali F, Feizpour C et al (2020) Routine venous thromboembolism prophylaxis may be inadequate in the hypercoagulable state of severe coronavirus disease 2019. Crit Care Med 48(9):e783-e790. https://doi.org/10.1097/ccm.0000000000 004466

44. Atallah B, Sadik ZG, Salem N et al (2021) The impact of protocol-based high-intensity pharmacological thromboprophylaxis on thrombotic events in critically ill COVID-19 patients. Anaesthesia 76(3):327-335. https://doi.org/10.1111/anae.15300

45. Panigada M, Bottino N, Tagliabue P et al (2020) Hypercoagulability of COVID-19 patients in intensive care unit. A report of thromboelastography findings and other parameters of hemostasis. J Thromb Haemost 18(7):1738-1742. https://doi.org/10.1111/jth. 14850

46. Spiezia L, Boscolo A, Poletto F et al (2020) COVID-19-related severe hypercoagulability in patients admitted to intensive care unit for acute respiratory failure. Thromb Haemost 120(6):998 1000. https://doi.org/10.1055/s-0040-1710018

47. Pavoni V, Gianesello L, Pazzi M et al (2020) Evaluation of coagulation function by rotation thromboelastometry in critically ill patients with severe COVID-19 pneumonia. J Thromb Thrombolysis 50(2):281-286. https://doi.org/10.1007/s11239-020-02130-7

48. Raval JS, Burnett AE, Rollins-Raval MA et al (2020) Viscoelastic testing in COVID-19: a possible screening tool for severe disease? Transfusion 60(6):1131-1132. https://doi.org/10.1111/trf.15847

49. Madathil RJ, Tabatabai A, Rabin J et al (2020) Thromboelastometry and D-dimer elevation in coronavirus-2019. J Cardiothorac Vasc Anesth 34(12):3495-3496. https://doi.org/10.1053/j.jvca. 2020.05.020

50. Kong R, Hutchinson N, Görlinger K (2020) Hyper- and hypocoagulability in COVID-19 as assessed by thromboelastometry. Two case reports. Korean J Anesthesiol. https://doi.org/10.4097/ kja.20327

51. Collett LW, Gluck S, Strickland RM et al (2021) Evaluation of coagulation status using viscoelastic testing in intensive care patients with coronavirus disease 2019 (COVID-19): an observational point prevalence cohort study. Aust Crit Care 34(2):155159. https://doi.org/10.1016/j.aucc.2020.07.003

52. Creel-Bulos C, Auld SC, Caridi-Scheible M et al (2021) Fibrinolysis shutdown and thrombosis in a COVID-19 ICU. Shock 55(3):316-320. https://doi.org/10.1097/SHK.0000000000001635 
53. Blasi A, von Meijenfeldt FA, Adelmeijer J et al (2020) In vitro hypercoagulability and ongoing in vivo activation of coagulation and fibrinolysis in COVID-19 patients on anticoagulation. $\mathrm{J}$ Thromb Haemost 18(10):2646-2653. https://doi.org/10.1111/jth. 15043

54. Vlot EA, Van den Dool EJ, Hackeng CM et al (2020) Anti Xa activity after high dose LMWH thrombosis prophylaxis in covid 19 patients at the intensive care unit. Thromb Res 196:1-3. https:// doi.org/10.1016/j.thromres.2020.07.035

55. Ibañez C, Perdomo J, Calvo A et al (2021) High D dimers and low global fibrinolysis coexist in COVID19 patients: what is going on in there? J Thromb Thrombolysis 51(2):308-312. https://doi.org/ 10.1007/s11239-020-02226-0

56. Nougier C, Benoit R, Simon M et al (2020) Hypofibrinolytic state and high thrombin generation may play a major role in SARSCOV2 associated thrombosis. J Thromb Haemost 18(9):22152219. https://doi.org/10.1111/jth.15016

57. Ranucci M, Ballotta A, Di Dedda U et al (2020) The procoagulant pattern of patients with COVID-19 acute respiratory distress syndrome. J Thromb Haemost 18(7):1747-1751. https://doi.org/ $10.1111 /$ jth. 14854
58. Zhang L, Yan X, Fan Q et al (2020) D-dimer levels on admission to predict in-hospital mortality in patients with Covid-19. J Thromb Haemost 18:1324-1329. https://doi.org/10.1111/jth. 14859

59. https://www.isth.org/news/517212/A-Systematic-Approach-forManaging-Venous-Thromboembolism-in-Patients-with-COVID19.htm. Accessed 3 Oct 2020

60. Lemos ACB, do Espírito Santo DA, Salvetti MC et al (2020) Therapeutic versus prophylactic anticoagulation for severe COVID-19: a randomized phase II clinical trial (HESACOVID). Thromb Res 196:359-366. https://doi.org/10.1016/j.thromres.2020.09.026

61. Bikdeli B (2020) Anticoagulation in COVID-19: randomized trials should set the balance between excitement and evidence. Thromb Res 196:638-640. https://doi.org/10.1016/j.thromres.2020.09.033

62. Talasaz AH, Sadeghipour P, Kakavand H et al (2021) Recent randomized trials of antithrombotic therapy for patients with COVID19: JACC state-of-the-art review. J Am Coll Cardiol 77(15):19031921. https://doi.org/10.1016/j.jacc.2021.02.035

Publisher's Note Springer Nature remains neutral with regard to jurisdictional claims in published maps and institutional affiliations. 